\title{
Research on the pipeline influence on the dynamic characteristics of a hydraulic servo system based on Hypneu
}

\author{
Zuo-Kai Liu, ${ }^{1, a}, J i a n-J u n ~ W e i^{2, b}$ \\ ${ }^{1,2}$ School of Mechanical Engineering, Guangxi University of Science and Technology, 545006 \\ Guangxi Liuzhou,China \\ aemail:1535197644@qq.com, bemail:13707803066@163.com
}

Keywords: Pipeline, Dynamic Characteristics, Simulation

\begin{abstract}
Previous studies have shown that the executive components and control components have great impacts on dynamic characteristics of a hydraulic system, while the impacts of auxiliary components in a hydraulic system are often deemed as less important. In this paper, the influence of the pipeline between hydraulic cylinder and electro-hydraulic servo valve on the dynamic characteristics of a steel strip tension control hydraulic servo system is studied with Hypneu simulation software. The results show that the pipeline has considerable influence, which should be taken into consideration in hydraulic system designing.
\end{abstract}

\section{Introduction}

In processing of steel strip, the tension within steel strip has a great influence on its thickness, width and flatness[1,2]. Every hydraulic component has its influence on the dynamic characteristics of steel strip tension control hydraulic servo system. Tubing in a hydraulic system is also important, since every component is connected by pipes. In this paper, with the help of Hypneu simulation software, the influence of the pipeline between the cylinder and servo valve on the dynamic characteristics of a steel strip tension control hydraulic servo system is studied[3,4].

\section{Pipeline Configuration}

Figure 1 is the working principle diagram of a steel strip tension control hydraulic servo system, composed of pump11, cylinder10, servo valve1, control device2, etc. Hydraulic components are connected by pipes. Due to different working conditions, the parameters of the pipeline between the hydraulic pump and actuator vary accordingly, this paper studies the influences of the pipeline between cylinder and servo valve on the dynamic characteristics under different parameters.

The formula for calculating the oil pipe inner diameter of the hydraulic system is:

$$
\text { Eq. } 1 \mathrm{~d}=2 \sqrt{\frac{Q}{\pi v}}
$$

Where $\mathrm{d}$ is the inner diameter of the pipe; $\mathrm{Q}$ is the flow rate through the pipe, $24 \mathrm{~L} / \mathrm{min}$; V is the flow velocity, $3 \mathrm{~m} / \mathrm{s}$. The hydraulic system flow rate is, flow velocity is, tubing length is $5 \mathrm{~m}$, and the inner diameter of the tube is thus calculated to be $13 \mathrm{~mm}$. 


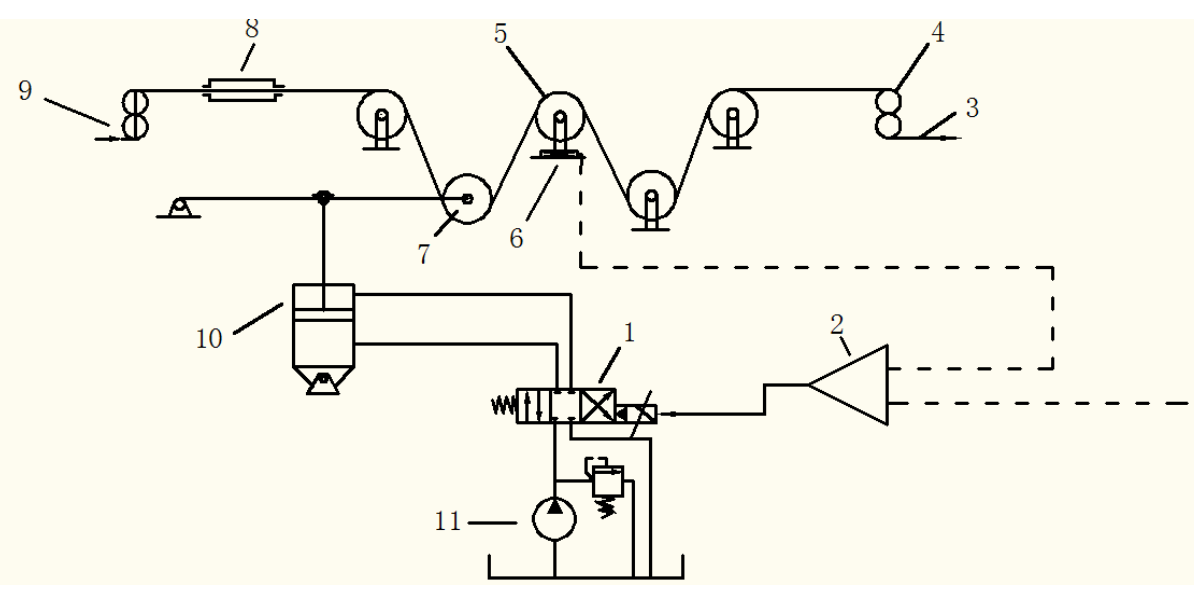

Fig.1 Working principle diagram of steel strip tension servo controlling system

\section{Simulation and Result Analysis}

\section{Simulation}

The load, or tension, is adjusted by controlling the displacement of cylinder 10, and is transduced by sensor 6 into feedback signal, which is also co-related to the cylinder displacement. Figure 2 is the simulation principle diagram, in which load is measured and converted to digital signal, applying on piston rod. By further arithmetic processing of cylinder displacement, the feedback signal is approximately generated. Assignments for the simulation system: electric motor speed: 800rpm; displacement of hydraulic pump: 30mL/rev, volume efficiency: $90 \%$; mechanical efficiency: 90\%; inner diameter of hydraulic cylinder: $100 \mathrm{~mm}$; piston rod diameter: 60mm; rod length: 900m; the stroke length of hydraulic cylinder: 700mm; oil viscosity: 20cst.

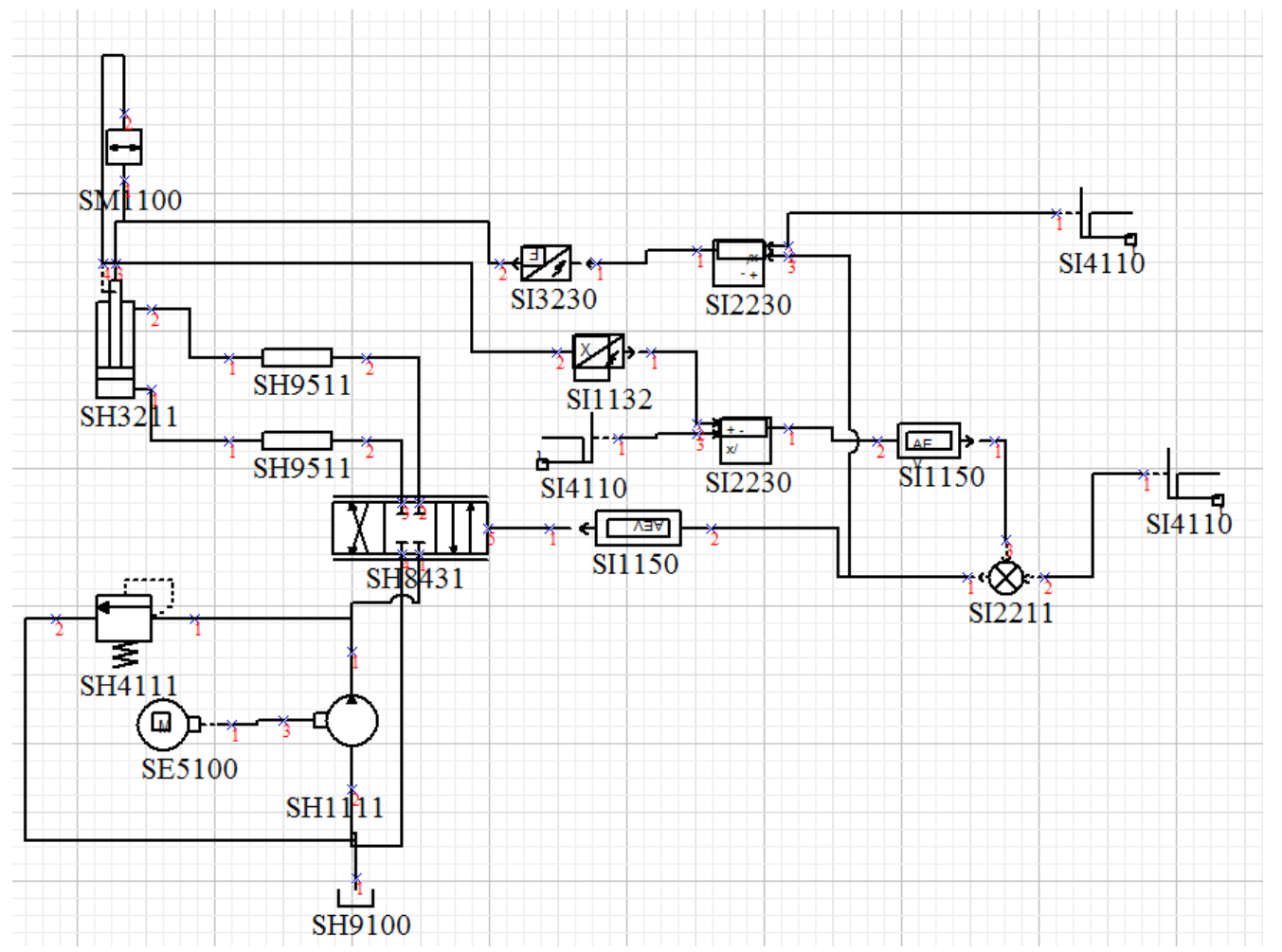

Fig.2 Simulation principle diagram of hydraulic servo system 


\section{Analysis of Simulation Results}

\section{The influence of pipe diameter on the dynamic characteristics of the system}

When the pipeline length is $5 \mathrm{~m}$, the dynamic response curves of hydraulic cylinder outlet pressure under different pipe diameter are shown in figure 3 and figure 4 , which indicate that with the increase of the pipe diameter, the maximum overshoot is gradually increased, and shock times and adjustment time are decreased gradually at first, and then gradually increased. The calculated diameter of the pipe is $13 \mathrm{~mm}$, but taking into account the stability of the system, from simulation, the optimal diameter $10 \mathrm{~mm}$ can be obtained when the pipe length is $5 \mathrm{~m}$.

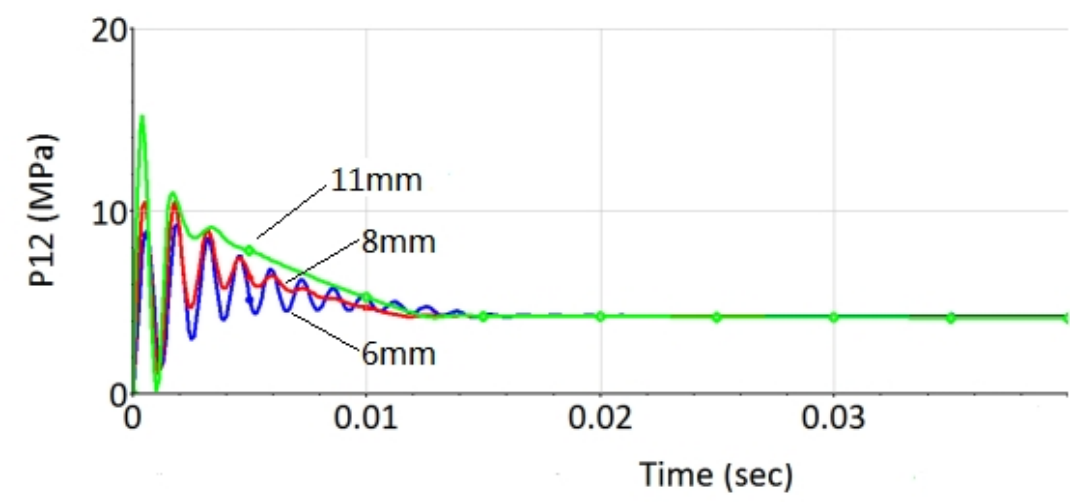

Fig.3 Response curves of cylinder outlet pressure under 6,8,11 mm pipe diameter

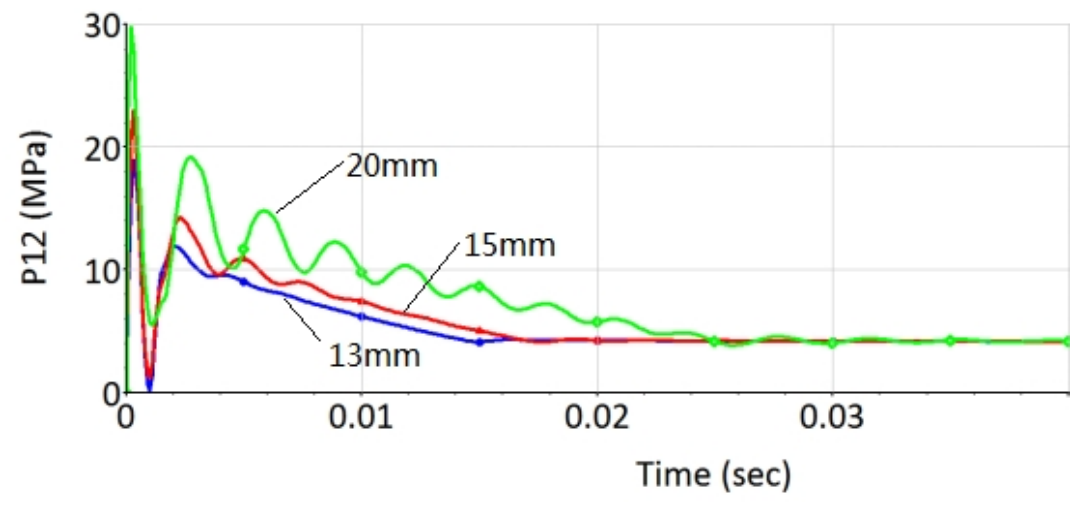

Fig.4 Response curves of cylinder outlet pressure under 13,15,20mm pipe diameter.

\section{The influence of pipe length on the dynamic characteristics of the system}

Due to different working conditions, the pipe lengths between the pump station and the hydraulic cylinder are different, so are their influences on dynamic characteristics of the system. Figure 5 is the dynamic response curves of hydraulic cylinder outlet pressure when the diameter of the pipe is $10 \mathrm{~mm}$ and the length of the pipeline is $5 \mathrm{~m}, 15 \mathrm{~m}$ or $25 \mathrm{~m}$. From figure 5 , with the increase of pipe length, the maximum overshoot and the shock times of the dynamic curve gradually increase, and the adjustment time becomes longer, indicating the system becomes less stable.

\section{The influence of pipe material on the dynamic characteristics of the system}

Figure 6 is the dynamic response curves of hydraulic cylinder outlet pressure under different pipe materials when the pipe length is $15 \mathrm{~m}$ and diameter is $10 \mathrm{~mm}$, It can be seen from figure 6 , that comparing to the rigid pipe, the shock adjustment time of flexible pipe is longer and the stability is worse. 


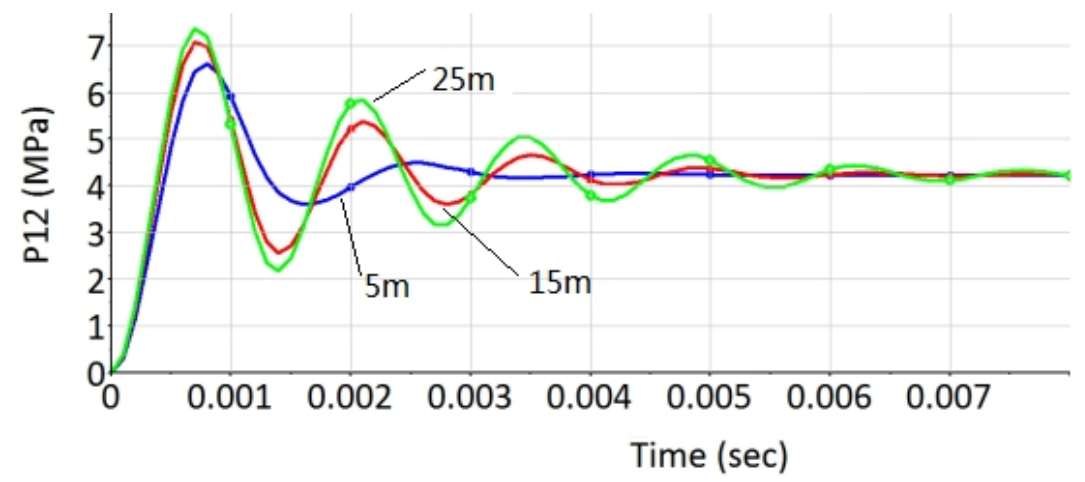

Fig.5 Response curves of cylinder outlet pressure with 5, 15, 25m pipe length.

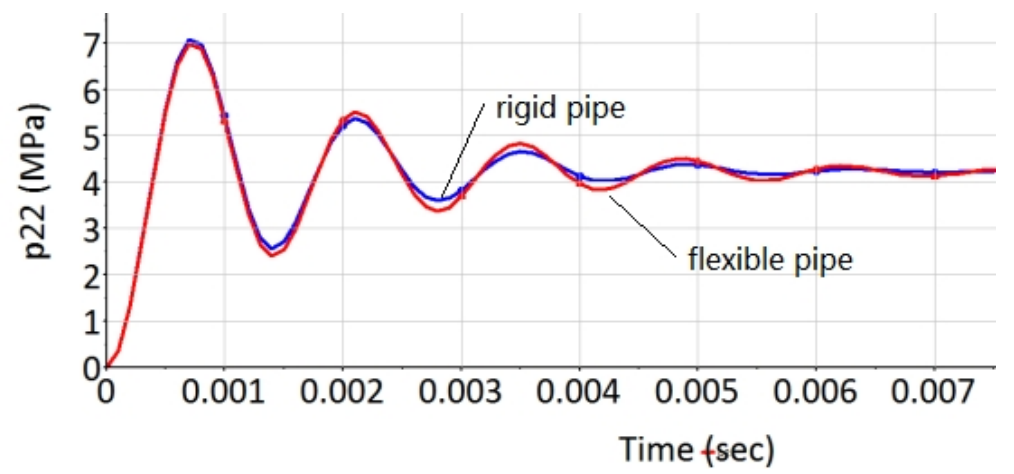

Fig.6 Response curves of cylinder outlet pressure with different pipe materials

\section{Conclusion}

The study indicates, in a, pipeline has significant influence on the system stability in steel strip tension control servo system. With the diameter increases, the maximum overshoot of dynamic response increases gradually, the times of shock and adjusting time decrease gradually at first, and then increase gradually; Longer pipe results in less stable system; The system has better stability using rigid pipe than using flexible one. With the help of Hypneu software, optimal design of pipeline can be obtained quickly and conveniently.

\section{Acknowledgement}

This research was financially supported by: Innovation Project of Guangxi Graduate Education 2015; Guangxi key Scientific and Technological Project \# 1598013-12.

\section{References}

[1] Wang Bojian, Zhu Chen. The effect of tension on the size of 2 Cr13 steel strip during heat treatment [J]. Metal products, 2015, (41) 1:29-32.

[2] Chen Zhenfang. The tension using of foreign steel strip continuous bright heat treatment furnace [J]. Shanghai Gangyan, 1993, 6:56-59.

[3] Guo Yanrong. Dynamic characteristics analysis of hydraulic support oil supply pipeline [D]. Taiyuan Shanxi: Taiyuan University of Technology, 2011.

[4]. Cen Yuwan. The influence of hydraulic pipeline on the stability of electro-hydraulic servo system[J]. Machine and Hydraulic, 1998,4:58-60. 